\title{
Studies of genetic variability of the hepatocyte nuclear factor-1a gene in an Indian maturity-onset diabetes of the young family
}

Jing Yang ${ }^{1 \dagger}$, Feng Jiang ${ }^{1 \dagger}$, Hui Guo ${ }^{1}$, Thadimacca Soniya ${ }^{1}$, Chun-xia Yan ${ }^{2}$, Zhu-fang Tian ${ }^{1}$ and Bing-yin Shi ${ }^{*}$

\begin{abstract}
Maturity-onset diabetes of the young (MODY), one of the specific types of diabetes mellitus, is a monogenetic disorder characterized by an autosomal dominant (AD) inheritance and $\beta$-cell dysfunction. To study an Indian family with clinical diagnosis of MODY and detect the genetic mutations in the aspect of molecular mechanism, seven blood samples were obtained from the diabetic patients of this pedigree and genomic DNA was extracted from peripheral leukocytes. The exon1, exon2 and exon4 of hepatocyte nuclear factor-1a (HNF-1a) gene were amplified by polymerase chain reaction. Then the products were sequenced and compared with standard sequences on gene bank. As a result, two mutations were detected in exon1. That was CTC $\rightarrow$ CTG (Leu $\rightarrow$ Leu) in codon17 and ATC $\rightarrow$ CTC (Ile $\rightarrow$ Leu) in codon27. 127L was speculated to have a close relationship with the glycometabolism and the pathogenesis of diabetes mellitus together with the putative novel mutation existed in this Indian pedigree. Meanwhile, one mutation of GGG $\rightarrow$ GGC (Gly $\rightarrow$ Gly) in codon288 of exon4 was detected in the proband. No mutations were found in exon2 but a $G \rightarrow$ T base substitution in the intron4 region among all seven samples was detected. It may have some potential effects on the onset of diabetes in this family, but we do not have any evidence right now. Although it requires further investigation on the function of mutations found in the intron region, our research may provide some clue for this issue and it deserves more attention.
\end{abstract}

Keywords: Maturity-onset diabetes of the young (MODY), Hepatocyte nuclear factor-1a (HNF-1a), Gene mutation, Single nucleotide polymorphism (SNP)

\section{Background}

Maturity-onset diabetes of the young (MODY) is a monogenetic disorder characterized by an autosomal dominant $(\mathrm{AD})$ inheritance and $\beta$-cell dysfunction. It is a genetically, metabolically and clinically heterogeneous type of noninsulin-dependent diabetes mellitus and is diagnosed by the following criteria: (1) onset of diabetes $\leq$ age 25; (2) transmission of the disease for at least three continuous generations; (3) control of hyperglycemia for a minimum period of 5 years without usage of insulin and absence of ketonuria at any time [1].

\footnotetext{
*Correspondence: shibingy@126.com

${ }^{\dagger}$ Jing Yang and Feng Jiang contributed equally to this work

1 Department of Endocrinology, The First Affiliated Hospital of Xi'an Jiaotong University School of Medicine, Xi'an 710061, People's Republic of China

Full list of author information is available at the end of the article
}

Different subtypes of MODY are caused by specific gene mutations. Six different genes have been confirmed to be responsible for the majority of MODY cases, according to which it is classified into MODY1-MODY6. For MODY2,the glucokinase gene (GCK) which encodes the glycolytic enzyme glucokinase and acts as a glucosesensor plays a key role in the regulation of glucose-stimulated insulin secretion [2-4]. The other five genes which encode the transcriptional factor including hepatocyte nuclear factor- $4 \alpha$ (HNF-4 $\alpha) /($ MODY1), hepatocyte nuclear factor- $1 \alpha$ (HNF-1 $\alpha) /($ MODY3), insulin promoter factor-1 (IPF-1)/(MODY4), hepatocyte nuclear factor- $1 \beta$ (HNF-1 $\beta) /($ MODY5) and NEUROD1 (MODY6) [5-9] can control the appropriate expression of $\beta$-cell. Nevertheless, there remains a portion of families whose virulence genes are still to be identified and they are named as MODYX [10]. 


\section{Methods}

The proband (IV7) was admitted to our hospital because of polydipsia and polyuria for 5 years, with onset of age of 13. Five years ago, she suffered from polydipsia and polyuria and was diagnosed as type 2 diabetes (FPG $\geq 10 \mathrm{mmol} / \mathrm{L})$. Then she was treated with Metformin (500 mg, bid) for 8 months and FPG maintained to be normal. During this period, she experienced hypoglycemia twice. Therefore, she stopped taking tablets and FPG maintained 5-7 mmol/L without drugs or insulin for over 4 years. Two weeks before the admission to the hospital, she had a fever and suffered from frequent emiction, urgent emiction, aching emiction as well as polydipsia and polyuria. Some biochemical examinations showed as follows: (1) Routine urinalysis: sugar(-), ketone(-), protein(1+). (2) FPG was $7.4 \mathrm{mmol} / \mathrm{L}$ and OGTT2h was $12.1 \mathrm{mmol} / \mathrm{L}$. (3) Oral glucose-insulin releasing test (OGIRT) showed that the fasting insulin level was $14.7 \mathrm{mmol} / \mathrm{L}$; OGIRT1h, $2 \mathrm{~h}$ and $3 \mathrm{~h}$ were $98.9,327.5$ and $89.4 \mathrm{mmol} / \mathrm{L}$, respectively. (4) $\mathrm{HbA}_{1} \mathrm{C}$ was $8.0 \%$. (5) Hepatic function tests, renal function tests and fasting blood lipids were normal. Consequently, she was diagnosed as diabetes along with urinary infection and treated with Metformin $(500 \mathrm{mg}$, bid) and antibiotics. Blood glucose became normal 10 days later. Simultaneously, the symptoms of urinary irritation disappeared and the urine protein returned to be negative.

We collected the information of the patient and her family members and found that it was consistent with autosomal dominant inheritance (Fig. 1). Meanwhile, it included a transmission of the disease through three generations, onset of diabetes $\leq 25$ years (IV6 and IV7), control of hyperglycemia for a minimum period of 5 years without insulin (except IV6) and absence of ketonuria at any time. Based on the clinical characteristics, this Indian family was considered to be a special pedigree of MODY.
There were eleven diabetic patients in this family and seven blood samples were drawn from them (Table 1).

All these seven patients were treated with hypoglycemic agent (except patient IV6 who used insulin when suffering from diabetes at the age of 13) without ketosis or acidosis at any time and the FPG was controlled below $6.1 \mathrm{mmol} / \mathrm{L}$. Other members in this family were confirmed to be normal with FPG $<6.1 \mathrm{mmol} / \mathrm{L}$ and $2 \mathrm{hPG}<7.77 \mathrm{mmol} / \mathrm{L}$. Based on the clinical features, we are prone to consider this pedigree to be MODY3.

In order to confirm our diagnosis, the DNA sequencing was conducted. Genomic DNA was extracted from peripheral leukocytes of all the seven patients. Then "hot" exons including exon1, exon 2 and exon 4 which cover the majority of the mutations of HNF-1 $\alpha$ gene were amplified by PCR using specific primers [11] (Table 2). Finally, the products were sequenced and compared with standard sequences on gene bank to find out possible mutations or polymorphisms which induced or related to the onset of diabetes in this family.

\section{Results}

Three mutations were detected in the coding regions of HNF-1 $\alpha$ gene. Two of them were located in exon1 (codon 17 and codon 27) and one of them was located in codon 288 of exon4 (Figs. 2, 3). CTC $\rightarrow$ CTG (Leu $\rightarrow$ Leu) mutation identified in codon17 (detected in II1, II2, III4, III5, IV6, IV7) was a silent mutation. $\mathrm{ATC} \rightarrow \mathrm{CTC}$ (Ile $\rightarrow$ Leu) mutation resided in codon27 (detected in II2, III4, IV6, IV7) was a missense mutation. Another GGG $\rightarrow$ GGC (Gly $\rightarrow$ Gly) mutation located in codon288 (detected in the proband) was also a silent mutation. All these mutations have been confirmed to be single nucleotide polymorphisms (SNPs). No mutations or polymorphisms were found in exon2. However, a base substitution of $\mathrm{G} \rightarrow \mathrm{T}$ was detected in the non-coding region of intron 4 in all seven patients.

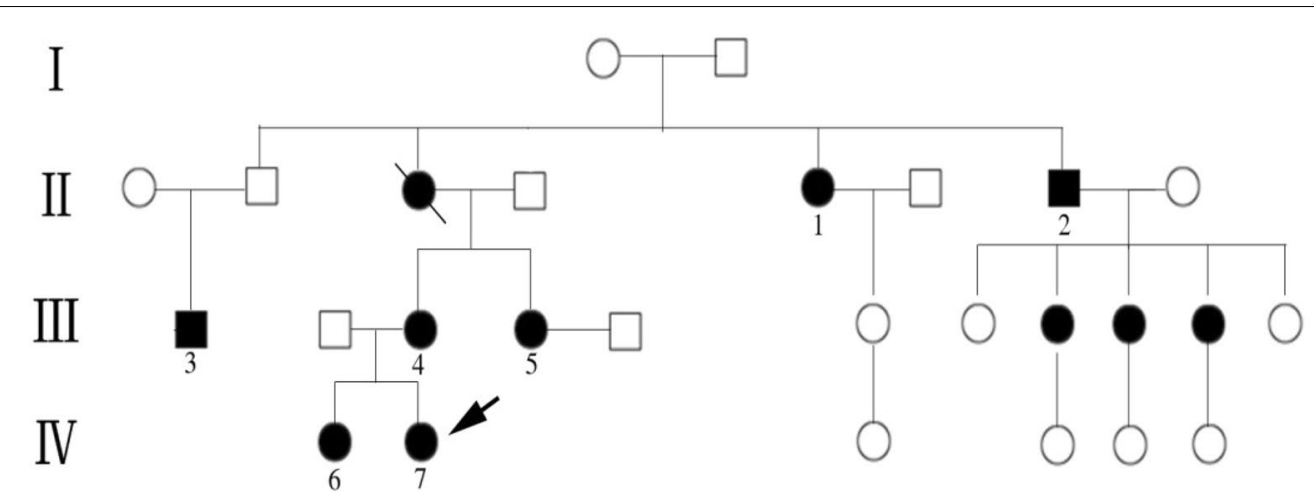

Fig. 1 Pedigree of this Indian family with MODY. Squares are males and circles are females. An arrow indicates the proband. Affected and unaffected subjects are indicated with filled and open symbols respectively 
Table 1 The clinical characteristics of this family

\begin{tabular}{llllll}
\hline Num. & Sex & $\begin{array}{l}\text { Age } \\
\text { (years) }\end{array}$ & $\begin{array}{l}\text { Onset of age } \\
\text { (years) }\end{array}$ & BMI $\left(\mathbf{k g} / \mathbf{m}^{\mathbf{2}}\right)$ & Therapy \\
\hline II1 & Female & 75 & 70 & 23.88 & Drugs \\
II2 & Male & 72 & 50 & 22.60 & Drugs \\
III3 & Male & 45 & 30 & 27.44 & Drugs \\
III4 & Female & 50 & 41 & 26.50 & Drugs \\
III5 & Female & 46 & 38 & 28.13 & Drugs \\
IV6 & Female & 21 & 13 & 28.93 & Insulin \\
IV7 & Female & 18 & 13 & 20.08 & Drugs \\
\hline
\end{tabular}

\section{Discussion}

HNF-1 $\alpha$ gene is located in chromosome $12 \mathrm{q} 24.2$ [12] and it plays a key role in regulating the expression of the genes associated with the glucose metabolism. Some researchers have shown that the HNF-1 $\alpha$ gene can directly regulate the expressions of insulin genes by the promoters. Meanwhile, many enzymes associated with the insulin secretion or gluconeogenesis are controlled by the HNF- $1 \alpha$ gene.

Shepherd [13] indicates that HNF-1 $\alpha$ mutations are highly penetrant, with $63 \%$ of mutation carriers having diabetes by the age of 25 years, $78.6 \%$ by 35 years, and $95.5 \%$ by 55 years. Those who have reached early middle age without having diabetes probably represent non-penetrance of the gene. These subjects frequently have a low body mass index, which can compensate for their $\beta$-cell defect by being sensitive to the insulin. In our study, five patients are diagnosed after the age of 30 years and two patients without obesity are diagnosed at a relatively old age (II1 and II2). We can explain it by the non-penetrance of the gene and the compensation for the $\beta$-cell defect. Another three patients (III3, III4 and III5) are overweight and diagnosed at a middle age. This may be due to a delayed diagnosis or a late onset of diabetes.

Ellard et al. [14] find that there are about 200 mutations in HNF-1 $\alpha$ responsible for MODY3 and the SNPs can increase the risk of type 2 diabetes by influencing the expression of HNF-1 $\alpha$ gene. In this research, we find that the I27L polymorphism of exon1 is presented in four patients (II2, III4, IV6, IV7). Recently, Holmkvist et al. [15] prove that I27L polymorphism would

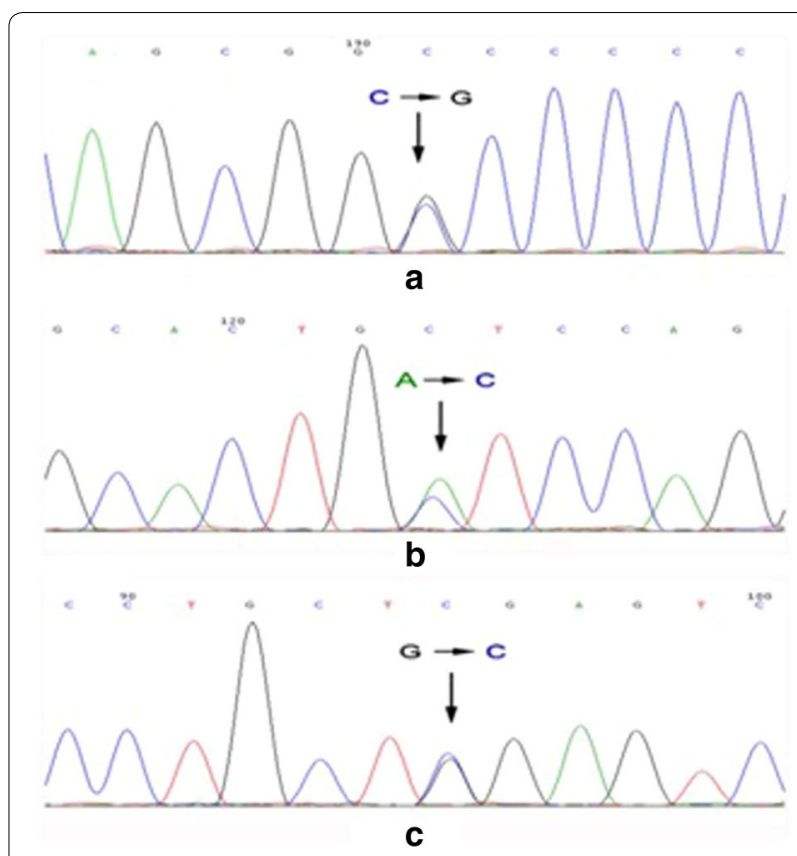

Fig. 2 Sequences screening map. a Codon 17 of exon1, an apparent doublet indicated $C \rightarrow G$ mutation can be seen in six members of this pedigree (II1, II2, III4, III5, IV6, IV7). b Codon27 of exon1, an apparent doublet indicated $A \rightarrow C$ mutation can be seen in four members of this pedigree (II2, III4, IV6, IV7). c Codon288 of exon4, an apparent doublet indicated $G \rightarrow$ C mutation can be seen in the proband of this pedigree (IV7)

reduce transcriptional activity in vitro, lower glucosestimulated insulin secretion in vivo, and increase the risk of type 2 diabetes especially in the overweighs and the elders. As we know, HNF-1 $\alpha$ is biologically active in a dimer form. The I27L is located in the dimerization domain and may affect the function of the protein. Furthermore, Isoleucine at position 27 is conserved among human, rat and mouse and it is located between two known MODY3 mutations (G20R and G31D). Conservation among different species and the location of this polymorphism suggest the biologic importance of this amino acid. Although the $\mathrm{I} 27 \mathrm{~L}$ polymorphism is not the direct cause of MODY3, there is evidence suggesting the significant roles of I27L polymorphism in the pathogenesis of diabetes. Here we report an Indian family though

Table 2 Sequences of primers used to amplify and directly sequence exons 1, 2, 4 of the human HNF-1 a gene

\begin{tabular}{llll}
\hline Exon & Sense primer $\left(\mathbf{5}^{\prime}-\mathbf{3}^{\prime}\right)$ & Antisense primer $\left(\mathbf{5}^{\prime}-\mathbf{3}^{\prime}\right)$ & $\begin{array}{c}\left.\text { Tm } \mathbf{~}^{\circ} \mathbf{C}\right) \\
\text { size } \mathbf{( b p )}\end{array}$ \\
\hline 1 & GGCAGGCAAACGCAACCCACG & GAAGGGGGGCTCGTTAGGAGC & 60 \\
2 & CATGCACAGTCCCCACCCTCA & CTTCCAGCCCCCACCTATGAG & 58 \\
4 & CAGAACCCTCCCCTTCATGCC & GGTGACTGCTGTCAATGGGAC & 390 \\
\hline
\end{tabular}




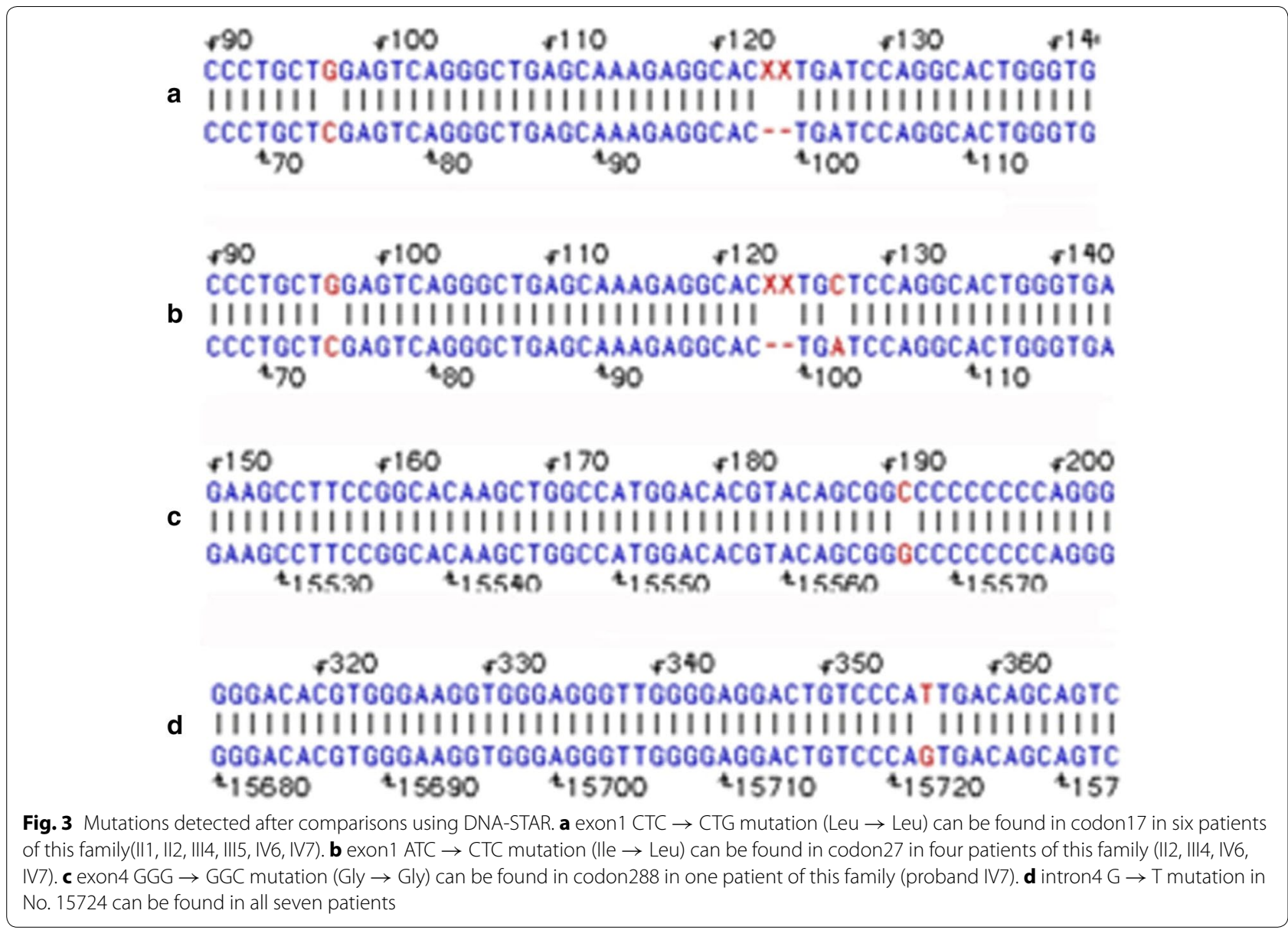

without novel mutations after amplifying exon1, exon2 and exon4. We find I27L polymorphism in four patients which has been demonstrated to play a significant role in the $\beta$-cell function and the insulin secretion. Meanwhile, there may be some possible virulence mutations not yet discovered that have a synergetic influence on the $\beta$-cell function together with $\mathrm{I} 27 \mathrm{~L}$ polymorphism.

In addition, there exists a base replacement of $G \rightarrow T$ among all seven patients in the non-coding region of intron4. There are a small number of reports [14] about the mutations in the introns of HNF- $1 \alpha$ gene or the influences on such mutations in the introns. The introns are regarded as nonsense segments and do not participate in encoding the protein. However, Mattick [16] indicates there is good evidence that introns can function as transposable elements and that nuclear introns derive from self-splicing group II introns which then evolve in partnership with the spliceosome. Furthermore, the introns are the "introns" for some specified genes but maybe are the "exons" for other specified genes, so the mutations in the introns may probably have an effect on the course of mRNA splicing and processing and may ultimately contribute to the expression of the genes as well as the function of the protein. Here our report about an Indian MODY family and the concordance of the $G \rightarrow T$ substitution detected in all seven patients deserves more attention. Although it requires further investigation on whether the mutation found in the intron region had relationships with the expression of HNF- $1 \alpha$ gene and the function of the protein, our research may provide some clue for this issue.

\footnotetext{
Abbreviations

MODY: maturity-onset diabetes of the young; HNF-1a: gene hepatocyte nuclear factor-1a; SNP: single nucleotide polymorphism; AD: autosomal dominant; GCK: glucokinase; HNF-4a: hepatocyte nuclear factor-4a; IPF-1: insulin promoter factor-1; HNF-1 $\beta$ : hepatocyte nuclear factor-1 $\beta$; FPG: fasting plasma glucose; OGTT: oral glucose tolerance test; OGIRT: oral glucose-insulin releasing test.
}

\section{Authors' contributions}

$J Y$ and FJ share first authorship by participating in its design and drafting the manuscript. GH conceived of the study. TS helped to collect the blood samples and detailed information. CXY and ZFT carried out the sequence alignment. BYS participated in its design and coordination. All authors read and approved the final manuscript. 


\section{Author details}

${ }^{1}$ Department of Endocrinology, The First Affiliated Hospital of Xi'an Jiaotong University School of Medicine, Xi'an 710061, People's Republic of China.

2 Department of Forensic Medicine, Xi'an Jiaotong University School of Medicine, Xi'an 710061, People's Republic of China.

\section{Acknowledgements}

This work was supported by Dr. Morhan Rao hospital in India. We gratefully acknowledge Dr. Mohan Rao in India for the assistance of drawing the blood samples and collecting the detailed information of the object family members.

\section{Competing interests}

The authors declare that they have no competing interests.

Ethics committee of the First Affiliated Hospital of Xi'an Jiaotong University School of Medicine states that this article is compliant with ethical guidelines (No. KYLLSL-2013-112-01).

Received: 21 February 2016 Accepted: 19 April 2016

Published online: 04 May 2016

\section{References}

1. Fajans SS. Scope and heterogeneous nature of MODY. Diabetes Care. 1990;13(1):49-64.

2. Froguel $P$, Vaxillaire $M$, Sun $F$, et al. Close linkage of glucokinase locus on chromosome $7 p$ to early-onset non-insulin-dependent diabetes mellitus. Nature. 1992;356(6365):162-4.

3. Matschinsky FM. Glucokinase as glucose sensor and metabolic signal generator in pancreatic $\beta$-cells and hepatocytes. Diabetes. 1990;39(6):647-52.

4. Postic C, Shiota M, Niswender KD, et al. Dual roles for glucokinase in glucose homeostasis as determined by liver and pancreatic beta cell-specific gene knock-outs using Cre recombinase. J Biol Chem. 1999;274(1):305-15.

5. Yamagata K, Furuta H, Oda N, et al. Mutations in the hepatocyte nuclear factor 4 a gene in maturity-onset diabetes of the young (MODY1). Nature. 1996:384(6608):458-60.

6. Yamagata K, Oda N, Kaisaki PJ, et al. Mutations in the hepatocyte nuclear factor 1a gene in maturity-onset diabetes of the young (MODY3). Nature. 1996;384(6608):455-8.

7. Stoffers DA, Ferrer J, Clarke WL, et al. Early-onset type-Il diabetes mellitus (MODY4) linked to IPF1. Nat Genet. 1997;17(2):138-9.

8. Horikawa Y, Iwasaki N, Hara M, et al. Mutation in hepatocyte nuclear factor $1 \beta$ gene (TCF2) associated with MODY. Nat Genet. 1997;17(4):384-5.

9. Malecki MT, Jhala US, Antonellis A, et al. Mutations in NEUROD1 are associated with the development of type 2 diabetes mellitus. Nat Genet. 1999;23(3):323-8.

10. Velho G, Robert JJ. Maturity-onset diabetes of the young (MODY): genetic and clinical characteristics. Horm Res. 2002;57(Suppl 1):29-33.

11. Kaisaki Pamela J, Menzel Stephan, Linder Tom, et al. Mutations in the hepatocyte nuclear factor-1 a gene in MODY and early-onset NIDDM: evidence for a mutational hotspot in exon4. Diabetes. 1997:46:528-35.

12. Fajans SS, Bell GI, Polonsky KS. Molecular mechanism and clinical pathophysiology of maturity-onset diabetes of the young. N Engl J Med. 2001;345(13):971-80

13. Shepherd M, Hattersley A, Sparkes A. Genetic testing in maturity onset diabetes of the young (MODY): a new challenge for the diabetic clinic. Pract Diabetes Int. 2001;18(1):16-21.

14. Ellard S, Colclough K. Mutations in the genes encoding the transcription factors hepatocyte nuclear factor 1 a (HNF1A) and 4a (HNF4A) in maturity-onset diabetes of the young. Hum Mutat. 2006;27(9):854-69.

15. Holmkvist J, Almgren P, Lyssenko V, et al. Common variants in maturityonset diabetes of the young genes and future risk of type 2 diabetes. Diabetes. 2008;57(6):1738-44.

16. Mattick John S. Introns: evolution and function. Curr Opin Genet Dev. 1994;4(6):823-31.

\section{Submit your next manuscript to BioMed Central and we will help you at every step:}

- We accept pre-submission inquiries

- Our selector tool helps you to find the most relevant journal

- We provide round the clock customer support

- Convenient online submission

- Thorough peer review

- Inclusion in PubMed and all major indexing services

- Maximum visibility for your research

Submit your manuscript at www.biomedcentral.com/submit
() Biomed Central 